\title{
PENGARUH PEMBERITAAN, KOMPETENSI DAN MOTIVASI TERHADAP KINERJA HUMAS PADA KOMPONEN DILINGKUP KEMENTERIAN DALAM NEGERI
}

\author{
MUH. ZHAFRI \\ Dosen Pendidikan Ekonomi, Universitas Pamulang \\ dosen01823@unpam.ac.id
}

\begin{abstract}
ABSTRAK
Tujuan penelitian adalah untuk mengetahui fenomena dan kesimpulan mengenai pengaruh variabel pemberitaan, kompetensi dan motivasi terhadap kinerja Pegawai Bidang Humas di lingkungan Kementerian Dalam Negeri. Teknik analisis data yang digunakan dalam penelitian ini yaitu: uji kualitas data validitas dan reliabilitas, analisis deskriptif, uji asumsi klasik normalitas, multikolinieritas dan heterokendatisitas, analisis regresi yaitu regresi sederhana dan berganda, parsial $\mathrm{t}$, simultan $\mathrm{F}$ dan koefesien determinasi. Pengambilan sampel menggunakan sampling jenuh yaitu penggunaan semua anggota populasi sebagai sampel. Responden dalam penelitian ini 135 Pegawai Negeri Sipil di bagian Humas Kementerian Dalam Negeri. Hasil uji penelitian sebagai berikut : hasil Uji Parsial t pertama menjawab H0 ditolak dan H1 diterima, yaitu bahwa Pemberitaan memiliki pengaruh signifikan terhadap Kinerja. Hasil Uji Parsial t kedua menjawab H0 ditolak dan H2 diterima, yaitu bahwa Kompetensi memiliki pengaruh signifikan terhadap Kinerja. Hasil Uji Parsial ketiga menjawab H0 diterima dan $\mathrm{H} 3$ ditolak, yaitu bahwa Motivasi tidak memiliki pengaruh signifikan terhadap Kinerja. Hasil Uji Simultan F menjawab H0 ditolak dan H4 diterima, yaitu bahwa Pemberitaan, Kompetensi dan Motivasi berpengaruh secara bersamasama terhadap Variabel Kinerja Pegawai Negeri Sipil bagian Humas di lingkungan Kementerian Dalam Negeri
\end{abstract}

Kata Kunci : Pemberitaan, Kompetensi, Motivasi, Kinerja

\section{PENDAHULUAN}

Peran humas dalam sebuah organisasi sangatlah penting. Dalam riset tentang kegiatan humas (public relations), ada dua peran besar yang secara konsisten muncul dalam kegiatan humas yaitu peran sebagai teknisi dan manajemen. Peran sebagai teknisi mewakili seni dari humas seperti menulis, mengedit, mengambil foto, menangani produksi 
komunikasi, membuat event spesial, dan melakukan kontak telepon dengan media.

$$
\text { Peran sebagai kepala divisi }
$$
berfokus pada kegiatan yang membantu organisasi dalam mengidentifikasi dan memecahkan masalah terkait humas. Kepala divisi humas melaksanakan tiga peran, pertama sebagai pemberi penjelasan, yaitu orang yang bekerja sebagai konsultan untuk mendefinisikan masalah, menyarankan pilihan, dan memantau implementasi kebijakan. Kedua sebagai fasilitator komunikasi, yaitu orang yang berada pada batas antara organisasi dengan lingkungan-nya yang menjaga agar komunikasi dua arah tetap berlangsung. Ketiga sebagai fasilitator pemecahan masalah, yaitu orang yang bermitra dengan manajer senior untuk mengidentifikasi dan memecahkan masalah Lattimore (2010 : 34).

Fungsi paling dasar humas dalam pemerintahan adalah membantu menjabarkan dan mencapai tujuan program pemerintahan, meningkatkan sikap responsif pemerintah, serta memberi publik informasi yang cukup untuk dapat melakukan pengaturan diri sendiri. Jadi, humas pemerintahan bertugas menjalankan kegiatan kebijakan dan pelayanan publik dengan memberikan ber-bagai informasi tentang kebijakan pemerintahan yang mengikat rakyat atau masyarakat.

\section{Kementerian Dalam Negeri dalam mempublikasikan peranan} teknis humas yang sudah dijelaskan dalam konsep pertama humas sebelumya, juga melakukan evaluasi secara berkala atas hal semua publikasi dilakukan oleh media masa yang disiarkan atau dipublikasikan seperti berita hard news, straight news, indepth news maupun patcher menyangkut Kementerian Dalam Negeri.

Indonesia Indicator (2018) IMM adalah sistem yang bekerja 24 jam secara real time, melakukan media monitoring untuk mengumpulkan content media online, cetak, dan TV. Kemudian, memberikan kajian se cara lengkap mulai dari timeline, influencers, media, sentiment, comparison, dan penelusuran terhadap detail obyek pemberitaan. Sistem mengambil dan mengelola miliaran data dari 2000 lebih media online seluruh dunia, 120 media cetak, 8 stasiun televisi dan media sosial.

Sistem mengukur opini masyarakat terhadap suatu issue, tokoh, organisasi, program, kebijakan, dan issue lain. Sistem akan secara otomatis menganalisis berita, laporan, dan masukan lain untuk menentukan sentimen masyarakat dan media terhadap issu yang ada.

Selain menjadi tugas pokok da lam menyelenggarakan fungsi hu bungan masyarakat melalui penge 
lolaan penyampaian pemberitaan bulanan yaitu laporan IMM, dalam rangka pembentukan opini masyarakat yang positif bagi pelaksanaan tugas dari semua lini bagian di Kementerian Dalam Nege ri. Eksistensi Humas dalam suatu lembaga/instansi pemerintah merupa kan keharusan secara fungsional dan operasional. Kelengkapan ini di anggap sangat penting karena falsafah Negara dari rakyat, oleh rakyat dan untuk rakyat seperti yang dikehendaki dalam bentuk Negara yang menganut sistem demokrasi. Sebagai Negara demokrasi, humas berfungsi melayani rakyat, karena rakyat turut mengawasi setiap kegiatan pemerintah, apabila tidak sesuai dengan aspirasi rakyat, rakyat secara cepat akan mengeritiknya.

Sumadiria (2005 : 64) Berita adalah sebuah informasi yang penting dan menarik perhatian serta menarik minat khalayak pendengar. Berita adalah laporan ten tang suatu peristiwa, opini, kecen derungan, situasi, kondisi interpretasi yang penting, menarik, masih baru dan harus disampaikan secepatnya ke pada khalayak. Berita adalah laporan tentang fakta atau ide yang dapat menarik perhatian pembaca, karena sesuatu yang luar biasa, penting, mencakup sisi human interest seperti humor, emosi dan ketegangan.

Tantangan terbesar dalam menjalankan organisasi pemerin tahan di era globalisasi ini adalah bagaimana melaksanakan pembangunan dengan tetap menerapkan komitmen yang tinggi berupa penerapan nilai luhur peradaban bangsa dan prinsip good governance dalam mewujudkan citacita bangsa dan negara. Dalam menyajikan laporan kerja Humas harus berkerja sama dengan divisidivisi lain yang ada di Kementerian Dalam Negeri, dikarenakan untuk sebagai bahan evaluasi dan pengambilan keputusan pada instansi/perusahaan yang berhubungan dengan instansi Kementerian Dalam Negeri.

Berdasarkan ekspose kementerian Kabinet Kerja 2016, kinerja Kementerian Dalam Negeri berdasarkan analisis pemberitaan Intelligent Media Management pada kabinet Jokowi-JK, selisih nilai presentase dengan pemberitaan tertinggi adalah $0,17 \%$. Dugaan dari nilai selisih tersebut hal ini disebapkan karena kurangnya ekspos/publikasi yang dilakukan oleh setiap komponen dilingkup Kementerian Dalam Negeri, dengan ini perlu diteliti lebih lanjut perihal Pemberitaan di Kementerian Dalam Negeri.

Fakta kompetensi di Kementerian Dalam Negeri pada divisi Humas, bahwa belum pernah melakukan pelatihan peningkatan kopentensi kehumasan di komponen lingkup Pusat Hubungan Masyarakat dan Penerangan. Pelatihan tersebut sangatlah penting dalam menunjang kerja para pegawai, dimana pegawai akan mengetahui standar yang harus dikerjakan dalam melaksanakan tugas maupun memecahkan suatu 
persoalan. Pelatihan ini diperlukan untuk meningkatkan pengetahuan pegawai dalam melakukan proses pemberitaan sehingga dapat dipublikasikan dan layak untuk dikomsumsi instansi maupun masyarakat.

Secara umum tujuan motivasi adalah untuk memotivasi pegawai dalam membantu perusahaan/ institusi mencapai keberhasilan. Pemberian motivasi ini perlu dikelola dengan baik oleh perusahaan, karena akan mempengaruhi kinerja pegawai. Dimana perusahaan menyadari bahwa motivasi kerja pegawai akan memberikan kontribusi yang baik untuk perusahaan. Dalam kenyataannya pemberian motivasi tidak selalu berjalan dengan baik, hal ini masih terjadi ketidakadilan dalam pemberian motivasi terhadap pegawai Humas Kementerian Dalam Negeri.

Rasa aman adalah salah satu dari indikator motivasi, dengan adanya rasa aman pegawai dapat bekerja dengan tenang sehingga menghasilkan kinerja yang maksimal, dalam pemberian fasum/fasilitas umum pada pegawai di Kementerian Dalam Negeri masih terjadi kesenjangan yang diterima kepada tiap-tiap pegawai. fasilitas umum/personal pegawai Humas Kementerian Dalam Negeri masih terjadi kesenjangan pada penerimaannya, dampak dari ketidaksamaan fasilitas yang diterima pegawai diduga menjadi penurunan kinerja pegawai, dengan ini penulis akan melakukan penelitian lebih lanjut perihal pemberian motivasi terhadap kinerja pegawai.

Kinerja pegawai pada dasarnya terbentuk setelah pegawai merasa adanya kepuasan, karena kebutuhannya terpenuhi dengan kata lain apabila kebutuhan pegawai belum terpenuhi sebagaimana mestinya maka kepuasan kerja tidak akan tercapai, dan pada hakikatnya Kinerja pegawai akan sulit terbentuk. Setiap orang yang bekerja digerakan oleh suatu motif. Motif pada dasarnya bersumber pada berbagai kebutuhan dasar individu atau dapat dikatakan bahwa kekuatan yang memotivasi seorang untuk bekerja giat dalam pekerjaanya tergantung dari hubungan timbal balik antar apa yang diinginkan atau dibutuhkan dari hasil pekerjaan tersebut dan seberapa besar keyakinan organisasi akan memberikan kepuasan bagi keinginannya sebagai imbalan atas usaha yang dilakukannya.

Benang merah perihal kajian kinerja pegawai yaitu, kinerja adalah hasil kerja (output) baik kualitas maupun kuantitas yang dicapai pegawai dalam periode waktu dalam melaksanakan tugas kerjanya sesuai dengan tanggung jawab yang diberikan kepadanya.

Fenomena kondisi kinerja pegawai Kementerian Dalam Negeri berdasarkan dari absensi pegawai yang berjumlah 135 dan terbagi dalam 12 unit eselon I di lingkungan Kementerian Dalam Negeri. Berikut data absensi yang diterima penulis 
dari bagian Biro Kepegawaian Kementerian Dalam Negeri :

Tabel Absensi 12 Bagian di Lingkungan

\begin{tabular}{|l|l|l|l|l|l|l|}
\hline \multirow{2}{*}{ No } & \multirow{3}{*}{ Bulan } & \multicolumn{2}{|l|}{ Keterangan } & Jml & Presen \\
\cline { 3 - 7 } & & Ijin & Sakit & $\begin{array}{l}\text { Alp } \\
\text { a }\end{array}$ & & \\
\hline 1 & Jan & 15 & 20 & 8 & 43 & $10,17 \%$ \\
\hline 2 & Feb & 12 & 18 & 7 & 37 & $8,75 \%$ \\
\hline 3 & Mar & 8 & 18 & 5 & 31 & $7,33 \%$ \\
\hline 4 & Apr & 9 & 17 & 8 & 34 & $8,04 \%$ \\
\hline 5 & Mei & 17 & 19 & 8 & 44 & $10,40 \%$ \\
\hline 6 & Juni & 15 & 20 & 3 & 38 & $8,98 \%$ \\
\hline 7 & Juli & 8 & 12 & 5 & 25 & $5,91 \%$ \\
\hline 8 & Agt & 7 & 17 & 4 & 28 & $6,62 \%$ \\
\hline 9 & Sept & 11 & 18 & 4 & 33 & $7,80 \%$ \\
\hline 10 & Okt & 12 & 21 & 8 & 41 & $9,69 \%$ \\
\hline 11 & Nov & 15 & 14 & 6 & 35 & $8,27 \%$ \\
\hline 12 & Des & 13 & 18 & 3 & 34 & $8,04 \%$ \\
\hline Jumlah & 142 & 212 & 69 & 423 & $100,00 \%$ \\
\hline
\end{tabular}

Kementerian Dalam Negeri

Sumber : Bagian Humas Pusat Penerangan Kemendagri, Tahun 2017

Berdasarkan dari absensi pada tabel di atas menunjukan rendahnya kedisiplinan pegawai, dari ketidakhadiran pegawai tersebut akan memperlambat pencapaian tujuan kerja yang sudah ditetapkan, dugaan rendahnya kedisiplinan ini yaitu kesenjangan pemberian fasum/ fasilitas umum yang sudah dijelaskan. Dengan ini dianggap perlu penulis melakukan penelitian lebih lanjut untuk mencari pemecahan masalah perihal kedisiplinan, agar absensi pada pegawai Humas Kementerian Dalam Negeri menjadi lebih baik.

Pada penelitian ini penulis berfokus pada 4 variabel yaitu Humas, Kompetensi dan Motivasi, karena variabel tersebut yang peneliti ingin mengetahui hubungan dan pengaruh terhadap kinerja pegawai Humas Kementerian Dalam Negeri. Sehingga perlu diteliti agar dapat diketahui tingkat signifikansinya terhadap kinerja pegawai pada organisasi. Adapun judul pada penelitian ini adalah "Pengaruh Pemberitaan, Kompetensi Dan Motivasi Terhadap Kinerja Humas Pada Komponen Dilingkup Kementerian Dalam Negeri."

\section{METODOLOGI PENELITIAN}

Jenis penelitian yang digunakan adalah dengan menggunakan metode penelitian deskriptif kuantitatif yang menekankan analisanya pada datadata numerikal (angka) yang selanjutnya diolah dengan metode statistika. Penelitian ini merupakan penelitian penjelasan asosiatif yang menguji hubungannya kausal antara variabel independen yaitu Pemberitaan, Kompetensi, Motivasi i, variabel dependen yaitu Kinerja.

Populasi dalam penelitian ini dengan jumlah 135, penentuan sampel menggunakan sampling jenuh, yaitu menggunakan semua anggota populasi sebagai sampel.

\section{HASIL DAN PEMBAHASAN Uji Validitas}

Hasil uji validitas dengan jumlah 40 pernyataan dari keempat variabel menunjukkan bahwa butir pernyataan variabel Pemberitaan (X1), Kompetensi (X2), Motivasi (X3) dan Kinerja (Y) dalam penelitian ini mempunyai nilai corrected item-total correlation lebih besar dari 0.17 dengan 135 responden. 


\section{Uji Reliabilitas}

\begin{tabular}{|c|c|c|c|c|}
\hline \multirow{2}{*}{ Variabel } & \multicolumn{2}{|c|}{$\begin{array}{c}\text { Responden \& } \\
\text { Item }\end{array}$} & \multicolumn{2}{|c|}{ Keterangan } \\
\hline & $\begin{array}{c}\text { Respo } \\
\text { nden }\end{array}$ & $\begin{array}{l}\text { N Of } \\
\text { Item }\end{array}$ & $\begin{array}{l}\text { Cronb } \\
\operatorname{ach} A\end{array}$ & Kategori \\
\hline Pemberitaan & 135 & 10 & 0.841 & $\begin{array}{c}\text { Sangat } \\
\text { Reliabel }\end{array}$ \\
\hline Kompetensi & 135 & 10 & 0.756 & Reliabel \\
\hline Motivasi & 135 & 10 & 0.854 & $\begin{array}{c}\text { Sangat } \\
\text { Reliabel }\end{array}$ \\
\hline Kinerja & 135 & 10 & 0.810 & $\begin{array}{c}\text { Sangat } \\
\text { Reliabel }\end{array}$ \\
\hline
\end{tabular}

Dari tabel di atas dapat disimpulkan bahwa seluruh pernyataan adalah sangat stabil dan konsisten. Hal ini dapat dilihat dari nilai Cronbach's Alpha yang jauh lebih besar dari tingkat Reliabel > 0,60 (batas standar).

\section{Uji Asumsi Klasik}

\section{Uji Normalitas}

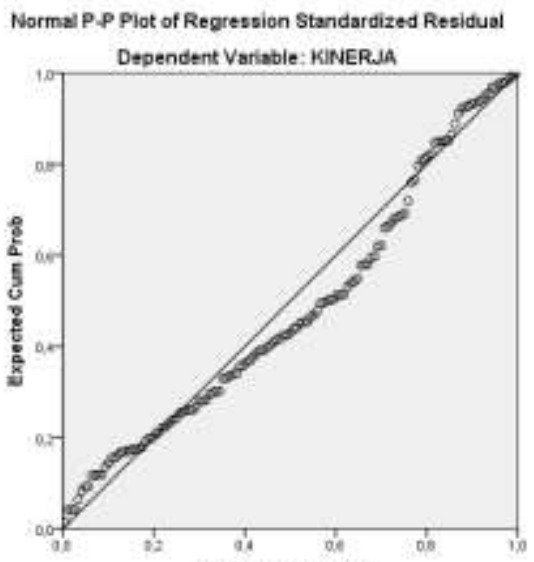

Melihat tampilăn gum prabia normal probability plot di atas, dapat disimpulkan bahwa pada grafik normal probability plot terlihat titiktitik menyebar di sekitar garis diagonal dan penyebarannya mengikuti arah garis diagonal, sehingga dapat disimpulkan bahwa data yang diuji berdistribusi normal.

\section{Uji Multikolinieritas}

\begin{tabular}{|l|l|c|c|}
\hline \multicolumn{4}{|c|}{ Coefficients $^{\text {a }}$} \\
\hline \multicolumn{2}{|l|}{ Model } & \multicolumn{2}{|c|}{ Collinearity Statistics } \\
\cline { 3 - 4 } \multicolumn{2}{|c|}{} & Tolerance & VIF \\
\hline \multirow{3}{*}{1} & (Constant) & & \\
\cline { 2 - 4 } & Pemberitaan & .493 & 20.028 \\
\cline { 2 - 4 } & Kompetensi & .838 & 10.194 \\
\cline { 2 - 4 } & Motivasi & .537 & 10.864 \\
\hline
\end{tabular}

Hasil perhitungan nilai Tolerance menunjukan variabel independen memiliki nilai Tolerance lebih dari 0.10 yang berarti tidak ada korelasi atau hubungan antara variabel independen yang nilainya lebih dari 95\%. Hasil perhitungan nilai variance inflation factor (VIF) juga menunjukan tidak ada satu variabel independen yang memiliki nilai VIF yang kurang dari 10.00, jadi dapat disimpulkan bahwa tidak terjadi multikolonieritas antara variabel independen dalam model regresi.

\section{Uji Heterokedastisitas}

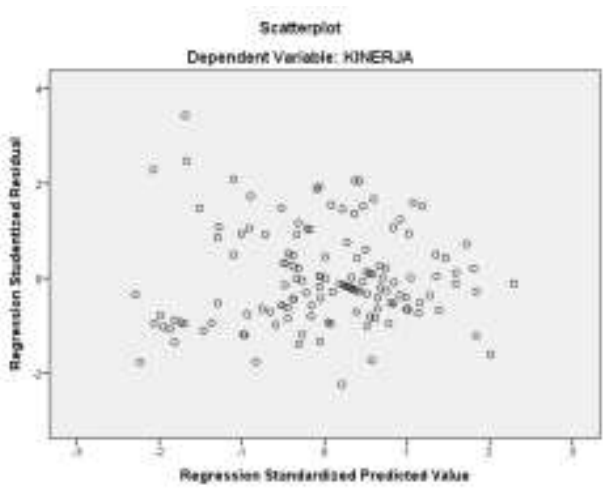

Dari grafik scatterplots terlihat bahwa titik-titik menyebar secara acak serta tersebar baik diatas maupun dibawah angka 0 pada sumbu Y. Hal ini dapat disimpulkan bahwa tidak terjadi masalah heteroskedastisitas pada model 
regresi, sehingga model regresi layak dipakai untuk memprediksi variabel Kinerja berdasarkan masukan dari variabel Pemberitaan, Kompetensi dan Motivasi.

\section{Analisis Regresi Linier Berganda}

Analisis regresi linier berganda ini digunakan untuk mengetahui ada tidaknya pengaruh dari variabel bebas terhadap variabel terikat. Sehingga dapat diketahui pengaruh variabel bebas (independen variable) yaitu Pemberitaan (X1), Kompetensi (X2), dan Motivasi (X3) terhadap variabel terikat (dependen variable) yaitu Kinerja (Y).

\begin{tabular}{|c|c|c|c|c|c|c|}
\hline \multicolumn{7}{|c|}{ Coefficients $^{\mathrm{a}}$} \\
\hline \multirow{2}{*}{ Model } & \multicolumn{2}{|c|}{$\begin{array}{c}\text { Unstandardized } \\
\text { Coefficients }\end{array}$} & $\begin{array}{c}\text { Standar } \\
\text { dized } \\
\text { Coeffici } \\
\text { ents }\end{array}$ & $\mathrm{t}$ & Sig. \\
\cline { 2 - 7 } & $\mathrm{B}$ & $\begin{array}{c}\text { Std. } \\
\text { Error }\end{array}$ & Beta & & \\
\hline \multirow{2}{*}{1} & (Constant) & 38.327 & 4.235 & & 9.051 & .000 \\
\cline { 2 - 7 } & Pemberitaan & .060 & .125 & .059 & 3.476 & .005 \\
\hline & Kompetensi & .023 & .081 & .026 & 2.278 & .001 \\
\hline & Motivasi & .016 & .127 & .015 & 1.423 & .002 \\
\hline
\end{tabular}

Berdasarkan tabel diatas diperoleh rumus regresi sebagai berikut: $\mathrm{Y}=38.327+0.060 \mathrm{X} 1+$ $0.023 \mathrm{X} 2+0.016 \mathrm{X} 3+\mathrm{e}$

Interprestasi dari regresi diatas adalah sebagai berikut:

1) Konstanta (a)

Ini berarti jika semua variabel bebas memiliki nilai (0) maka variabel terikat (kinerja) sebesar 38.327.

2) Pemberitaan (X1) terhadap Kinerja (Y)

3) Nilai koefesien Pemberitaan untuk variabel X1 sebesar 0.060.
Hal ini mengandung arti bahwa setiap kenaikan Pemberitaan satu satuan maka variabel Kinerja (Y) akan naik sebesar 0.060 dengan asumsi bahwa variabel bebas yang lain dari model regresi adalah tetap.

4) Kompetensi (X2) terhadap Kinerja (Y)

Nilai koefesien Kompetensi untuk variabel X2 sebesar 0.023 . Hal ini mengandung arti bahwa setiap kenaikan Kompetensi satu satuan maka variabel Kinerja (Y) akan naik sebesar 0.023 dengan asumsi bahwa variabel bebas yang lain dari model regresi adalah tetap.

5) Motivasi (X3) terhadap Kinerja (Y)

Nilai koefesien Motivasi untuk variabel X3 sebesar 0.016. Hal ini mengandung arti bahwa setiap kenaikan Motivasi satu satuan maka variabel Kinerja (Y) akan naik sebesar 0.016 dengan asumsi bahwa variabel bebas yang lain dari model regresi adalah tetap.

\section{Uji Signifikan Parameter Individual (Uji Statistik t)}

Uji $t$ dilakukan untuk mengetahui besarnya pengaruh masing-masing variabel independen secara individual terhadap variabel dependen. Pengujian pengaruh antara variabel Pemberitaan (X1) Kompetensi (X2) Motivasi (X3) terhadap Kinerja (Y). 


\begin{tabular}{|c|c|c|c|c|c|c|}
\hline \multicolumn{7}{|c|}{ Coefficients $^{\mathrm{a}}$} \\
\hline & \multirow{2}{*}{ Model } & \multicolumn{2}{|c|}{$\begin{array}{l}\text { Unstandardized } \\
\text { Coefficients }\end{array}$} & \multirow{2}{*}{ 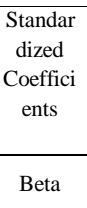 } & \multirow{2}{*}{$\mathrm{t}$} & \multirow{2}{*}{ Sig. } \\
\hline & & B & $\begin{array}{c}\text { Std. } \\
\text { Error }\end{array}$ & & & \\
\hline \multirow{2}{*}{1} & (Constant) & 38.327 & 4.235 & & 9.051 & .000 \\
\hline & Pemberitaan & .060 & .125 & .059 & 3.476 & .005 \\
\hline & Kompetensi & .023 & .081 & .026 & 2.278 & .001 \\
\hline & Motivasi & .016 & .127 & .015 & 1.423 & .002 \\
\hline
\end{tabular}

Interprestasi dari tabel 4.18 di atas dapat diperoleh hasil sebagai berikut:

1) Pemberitaan (X1) terhadap Kinerja (Y)

Terlihat pada kolom Coefficients model 1 terdapat nilai sig 0.005 . Nilai sig lebih kecil dari nilai probabilitas 0.05 , atau nilai $0.005<0.05$, maka $\mathrm{H} 1$ diterima dan H0 ditolak. Variabel X1 mempunyai t hitung yakni 3.476 dengan $\mathrm{t}$ tabel 1.656. jadi $\mathrm{t}$ hitung $>\mathrm{t}$ tabel dapat disimpulkan bahwa variabel $\mathrm{X} 1$ memiliki kontribusi terhadap $\mathrm{Y}$. nilai $\mathrm{t}$ positif menunjukan bahwa variabel $\mathrm{X} 1 \quad$ mempunyai hubungan yang searah dengan $\mathrm{Y}$. Kesimpulan dari hasil uji $\mathrm{t}$ ini yaitu variabel Pemberitaan memiliki pengaruh signifikan terhadap Kinerja.

2) Kompetensi (X2) terhadap Kinerja (Y)

Terlihat pada kolom Coefficients model 1 terdapat nilai sig 0.001 . Nilai sig lebih kecil dari nilai probabilitas 0.05 , atau nilai $0.001<0.05$, maka $\mathrm{H} 2$ diterima dan H0 ditolak. Variabel X2 mempunyai $\mathrm{t}$ hitung yakni 2.278 dengan $\mathrm{t}$ tabel 1.656. jadi $\mathrm{t}$ hitung $>\mathrm{t}$ tabel dapat disimpulkan bahwa variabel $\mathrm{X} 2$ memiliki kontribusi terhadap Y. Nilai $t$ positif menunjukkan bahwa variabel X2 mempunyai hubungan yang searah dengan Y. Kesimpulan dari hasil uji $\mathrm{t}$ ini yaitu variabel Kompetensi memiliki pengaruh signifikan terhadap Kinerja.

3) Motivasi (X3) terhadap Kinerja (Y)

Terlihat pada kolom Coefficients model 1 terdapat nilai sig 0.002 . Nilai sig lebih kecil dari nilai probabilitas 0.05 , atau nilai $0.002<0.05$, maka H3 diterima dan H0 ditolak. Variabel X3 mempunyai t hitung yakni 1.423 dengan $\mathrm{t}$ tabel 1.656. jadi $\mathrm{t}$ hitung $<\mathrm{t}$ tabel dapat disimpulkan bahwa variabel X3 tidak memiliki kontribusi terhadap Y. Nilai $\mathrm{t}$ positif menunjukan bahwa variabel X3 tidak mempunyai hubungan yang searah dengan $\mathrm{Y}$. Kesimpulan dari hasil uji $\mathrm{t}$ ini yaitu variabel Motivasi tidak memiliki pengaruh signifikan terhadap Kinerja.

Uji Signifikan Simultan (Uji Statistik F)

Uji $\mathrm{F}$ digunakan untuk menguji variabel-variabel bebas secara bersama-sama terhadap variabel terikat, uji $\mathrm{F}$ dilakukan untuk mengetahui pengaruh variabelvariabel independen secara simultan (bersama-sama) terhadap variabel dependen 


\begin{tabular}{|c|c|c|c|c|c|c|}
\hline \multicolumn{7}{|c|}{ ANOVA $^{\text {a }}$} \\
\hline \multicolumn{2}{|c|}{ Model } & $\begin{array}{c}\text { Sum of } \\
\text { Squares }\end{array}$ & df & Mean Square & F & Sig. \\
\hline \multirow{3}{*}{1} & Regression & 10.272 & 3 & 3.424 & 3.387 & .005 \\
\cline { 2 - 8 } & Residual & 2397.061 & 131 & 18.298 & & \\
\cline { 2 - 8 } & Total & 2407.333 & 134 & & & \\
\hline
\end{tabular}

Dari tabel diatas diperoleh nilai $\mathrm{F}$ hitung sebesar 3.387 dengan nilai probabilitas sig 0.005 . nilai $\mathrm{F}$ hitung 3.387>2.44 dan nilai sig lebih kecil dari nilai probabilitas 0.05 atau nilai $0.005<0.05$. Maka $\mathrm{H} 4$ diterima dan HO ditolak, hasil ini menunjukan variabel Pemberitaan, Kompetensi dan Motivasi berpengaruh secara bersama-sama terhadap Variabel Kinerja.

\section{Uji Koefisien Determinasi R2 Square}

\begin{tabular}{|c|c|c|c|c|}
\hline \multicolumn{4}{|c|}{ Koefisien } & \\
\hline \multirow{7}{*}{\multicolumn{5}{|c|}{$\begin{array}{l}\text { digunakan untuk mengetah } \\
\text { seberapa besar hubungan da } \\
\text { beberapa variabel dalam pengertia } \\
\text { yang lebih jelas.. Dalam bahas } \\
\text { sehari-hari adalah kemampua } \\
\text { variabel bebas untuk berkontribu } \\
\text { terhadap variabel tetapnya dalar } \\
\text { satuan persentase }\end{array}$}} \\
\hline & & & & \\
\hline & & & & \\
\hline & & & & \\
\hline & & & & \\
\hline & & & & \\
\hline & & & & \\
\hline \multicolumn{5}{|c|}{ Model Summary } \\
\hline & $\mathrm{R}$ & $\begin{array}{c}\mathrm{R} \\
\text { Square }\end{array}$ & $\begin{array}{l}\text { Adjusted R } \\
\text { Square }\end{array}$ & $\begin{array}{l}\text { Std. Error of the } \\
\text { Estimate }\end{array}$ \\
\hline & & & & \\
\hline & & & & \\
\hline
\end{tabular}

Berdasarkan Tabel "Model Summary" dapat disimpulkan bahwa variabel Pemberitaan, Kompetensi dan Motivasi berpengaruh sebesar $84.7 \%$ terhadap variabel Kinerja, sedangkan $\quad 15.3 \%$ dipengaruhi variabel lain yang tidak diteliti. Karena nilai $\mathrm{R}$ Square dibawah 5\% atau cenderung mendekati nilai 0 maka dapat disimpulkan kemampuan variabel-variabel independen dalam menjelaskan variasi variabel amat terbatas.

\section{KESIMPULAN}

1. Pemberitaan terhadap Kinerja pegawai bidang Humas di Kementerian Dalam Negeri, hasil uji t $3.476>1.656$ maka variabel Pemberitaan berpengaruh signifikan terhadap Kinerja pegawai bidang Humas Kementerian Dalam Negeri.

2. Kompetensi terhadap Kinerja pegawai bidang Humas di kementerian Dalam Negeri, hasil uji t 2.278>1.656 maka variabel Kompetensi berpengaruh signifikan terhadap Kinerja pegawai bidang Humas Kementerian Dalam Negeri.

3. Motivasi terhadap kinerja pegawai bidang Humas di Kementerian Dalam Negeri, hasil uji t $1.423<1.656$ maka variabel Motivasi tidak berpengaruh signifikan terhadap Kinerja pegawai bidang Humas Kementerian Dalam Negeri.

4. Hasil uji F 3.387>2.44. Hasil Koefesien Korelasi $6.5 \%$ dan Koefesien Determinasi $84.7 \%$ maka variabel Pemberitaan, Kompetensi dan Motivasi berpengaruh serta berkontribusi signifikan secara bersama terhadap Kinerja Pegawai 
bidang Humas Kementerian Dalam Negeri.

\section{REFERENSI}

Abraham Maslow. (2006). Motivation and Personality, Rajawali, Jakarta

Agustino, Leo,(2008), Dasar Dasar Kebijakan Publik, Bandung, Alfabeta

Arikunto, Suharsimi, (2011), Prosedur Penelitian Suatu Pendekatan Praktik, Edisi, Jakarta, PT, Rineka Cipta

Azhar, (2011). Media Pembelajaran, Jakarta, PT Raja Grafindo Persada

Basri, Rivai, (2005). Performance Appraisal, PT Raja Grafindo, Persada, Jakarta

Charnley, Mitchel V, (2001). "Reporting", Ghalia Indonesia

Dale, Timpe, (1999). Seri Manajemen Sumber Daya Manusia, Yogyakarta, Gramedia Effendy, Onong Uchjana, (2003). Hubungan Masyarakat Suatu Studi Komunikologis Bandung, PT Remaja Rosda Karya

Garratt (2003). Organization Behaviour, Gramedia, Jakarta Ghozali, Imam, (2005). Aplikasi Analisis Multivariate dengan SPSS, Semarang, Badan Penerbit UNDIP

Handayanigrat, Soewarno, (1996). Pengatur Ilmu Admi, Manajemen, Jakarta, CV, Masasung

Haris,Sumadiria, (2005). Jurnalistik Indonesia, Menulis Berita dan Feature, Panduan Praktis
Jurnalis Profesional, Penerbit PT, Remaja

Kencana, dkk, (2003). Ilmu Administrasi Publik, Rineka Cipta, Jakarta.

Lattimore, dkk, (2010). Public Relations, Profesi dan Praktik, Jakarta, Salemba

Mangkunegara, tahun (2006). Perencanaan dan, Pengembangan Manajemen Sumber Daya Manusia, Penerbit, PT Refika

Moeheriono, (2009). Pengukuran Kinerja Berbasis kompetensi Bandung, CV Pustaka Setia

Muchdarsyah, (2007). Produktivitas Apa dan Bagaimana kinerja, Penerbit Bumi Aksara

Nawawi, (2005). Manajemen Sumber Daya Manusia Untuk Bisnis Yang Kompetitif, Cetakan Ke-4, Gajah Mada Univercity Press

Nazir, Moh, (2005). Metode Penelitian, Jakarta, Ghalia Indonesia

Notoatmodjo, Soekidjo, (2003). Pendidikan Dan Perilaku Kesehatan, Rineka, Cipta, Jakarta

Nurianna Thoha, (2008). Kompetensi komunikasi Plus, Teori, Desain, Kasus dan Penerapan untuk HR dan Organisasi yang Dinamis, Rineka, Cipta, Jakarta

Rivers, W,L, J,W Jensen, dan T, Peterson, (2008). Media Massa dan Masyarakat, Modern CV Pustaka Setia, bandung

Robbins, Stephen, (2008). Organizational Behaviour, 
Gramedia Pustaka Utama, Jakarta

Ruky, (2006). Sistem Manajemen

Kinerja, Jakarta , PT, Gramedia,

Pustaka utama

Siagian, Sondang,

Kepemimpinan Organisasi \&

Perilaku Administrasi, Jakarta,

Penerbit Gunung Agung

Silalahi, Ulber, (2009). Metode

Penelitian Sosial, Yogyakarta

Simon Devung, (2009), Pengantar

Ilmu Administrasi dan

Manajemen, Jakarta,

Departemen Pendidikan dan

Kebudayaan

Sugiyono, (2010). Metode Penelitian

Kuantitatif Kualitatif \& RND,

Bandung, Alfabeta

Suyatna, (2010). Metode Penelitian

Administrasi, Gramedia, Jakarta

Sulistyo Basuki, (2004). Pengantar

Ilmu Perpustakaan, Jakarta,

Gramedia Pustaka Utama

Sumadiria, AS Haris, (2008).

Jurnalistik Indonesia, Gramedia

Pustaka Utama

Toha, dkk, (2008). Kompetensi dan

Kinerja pegawai, Jakarta, Pusat

Penerbitan, Universitas Terbuka

Veithzal Rivai, (2004). "Manajemen

Sumber Daya Manusia Untuk

Perusahaan, Cetakan Pertama,

Jakarta, PT, Raja Grafindo

Persada

Wibowo, (2013). Manajemen

Kinerja, Jakarta, Rajawali Pers

Wiryawan, (2012). Evaluasi Kinerja

Sumber Daya Manusia Teori

Aplikasi dan Penelitian, Jakarta
Zwell Mitchel V, (2007). Charnley dalam bukunya Reporting edisi III 